Page 62

Received 11 July 2019 Revised 23 Sep 2019 Accepted 30 Oct 2019

\section{THE TIME IS ALREADY HERE: Tax Administrations in Digital Evolution}

\author{
KsenijaCipek \\ Ministry of Finance, Croatia
}

\begin{abstract}
Tax administrations around the world face a new era of digital evolution. Tax policy is one of the most important policies of each country, so the time of new digital challenges cannot be ignored. Tax administrations have a huge amount of information that needs to be safe, confidential and disposed of in accordance with regulations and prescribed procedures. In addition to collecting tax revenues, one of the tasks of the tax administration is to serve taxpayers. In digital era, they try to ease the administrative burden on taxpayers using new technologies. New technologies are also used for the purpose of preventing tax frauds and determining the risk of taxpayers. What kinds of new technologies will be used by tax administrations depends on their estimate, but cannot be overlooked if they want to be efficient in their work. Tax legislation is also faced with new challenges such as the occurrence of crypto currency. The subject of this article is the emphasis on the possibilities of applying new technologies in tax administrations, the relationship between tax legislation and technology, the possibilities of digitization and the consideration of crypto currency issues.
\end{abstract}

Keywords: legislation, technology, digitalisation, new business models, crypto currency, blockchain

Paper Type: conceptual paper

\section{NBR}

NBR-19-0112

NUST Business Review

Vol. 01 , No. 01

10, 2019

pp. $62-72$

c) NUST Business School 
NBR

1,1

Page 63

\section{INTRODUCTION}

The Fourth Industrial Revolution represents a fundamental change in the way we live, work and relate to one another. It is a new chapter in human development, enabled by extraordinary technological advances and commensurate with those of the first, second, and third industrial revolutions. These advances are merging the physical, digital and biological worlds in ways that create both huge promise and potential peril. The speed, breadth and depth of this revolution is forcing us to rethink how countries develop, how organisations create value and even what it means to be human as well. The Fourth Industrial Revolution is about more than just technologydriven change; it is an opportunity to help everyone, including leaders, policy-makers and people from all income groups and nations, to harness converging technologies in order to create an inclusive, human-centred future. The real opportunity is to look beyond technology, and find ways to give the greatest number of people the ability to positively impact their families, organisations and communities.

From the broad definition of the influence of The Fourth Industrial Revolution to the world as it has been known so far, this text attempts to sum up the most important new technological challenges that tax administrations face and the impact on the overall tax law system. The Fourth Industrial Revolution can be called digital evolution in terms of technological achievements. The new digital era creates new challenges, but also new, absolutely amazing, and great opportunities that we must know how to go about it. Especially in the area of tax policy which is always of vital importance for the whole society. The emergence of Artificial Intelligence, Machine Learning, Blockchain and Distributed Ledger Technology, opens up tax administrations to the way of analysis, and allows for testing the application of the best solutions. The time is already here!

What are the key points that tax administrations, at the time of the Fourth Industrial Revolution, should pay attention to? Tax legislation is the basis for the functioning of the tax system as a whole. The extent to which new technologies will affect tax laws and whether the paradigm we know so far will change, is one of the fundamental questions that need to be considered. It is necessary to examine how the digitalisation and advanced analytics will affect business processes within tax administrations and how they can take advantages of digitalisation in efficient tax collection, as well as in improving their services and reducing the administrative burden on taxpayers.

New business models also bring unique ways of performing taxpayer business activities. Tax administrations must be prepared to classify new ways of conducting business activities and be able to identify them. Crypto currencies are becoming more and more common in day-to-day business and people's lives. The new era may be also marked by the emergence of crypto currency. At the outset, tax administrations must pay particular attention to their development and role in business activities so that they can adequately apply tax treatment. Tax administrations must continually review the advantages and disadvantages of new technologies, especially Blockchain and Distributed Ledger Technology. 
The article focuses on the following key issues for tax administrations around the world.

NBR

1,1

Page 64

\section{IMPACT OF NEW TECHNOLOGIES ON TAX LEGISLATION}

The paradigm of legislation that we know is based on one principle: technology always follows legislation! Today, such a paradigm is no longer acceptable. We can imagine a tax policy that can have very good goals, but if does not follow technological development, a positive result can be totally omitted. Tax legislation should, among other things, be understandable and reduce the administrative burden on entrepreneurs and citizens (of course, it is also necessary to reduce the tax burden, but that depends on a number of factors within each country).

How has the paradigm that we know changed, and to what extent? Technology allows a range of tools that can have a positive impact on tax policy. If tax legislation follows the goals of simplicity, visibility, comprehensiveness, structuring, transparency, availability, and affects the decrease of taxpayers' administrative burden, the tax policy objectives will be positive. In most countries, efforts are being made and tools are provided for the utmost openness of tax and customs administration to taxpayers, which contribute to their voluntary tax compliance. For example, the electronic services provided by the tax and customs administration. Filing of prescribed forms and reports online is one of the tools. Entrepreneurial insights are also ensured in his tax or customs duties. The taxpayers' rights are available on the official web pages of tax and customs administrations. These administrations electronically send tax payers information relevant to their lawful and timely tax compliance. Such a two-way approach between taxpayers and tax and customs administrations should necessarily be encouraged (as well as in other states and local bodies) in all legal issues other than those that can be reasonably justified as necessary for communication without using electronic services.

Of course, it will require the amendment of a series of regulations in order to create a legal basis for the same. However, if we want to achieve the goals of tax policy that will stimulate the overall economic policy, that is necessary. Moreover, savings will also be made on side of state institutions which is very important. An expensive state administration is not an option. For example, until recently, the usual delivery of decisions and acceptance of complaints (either by state institutions or by taxpayers and citizens) was "in paper". With the development of certified signatures, eadministrative offices and digital archives such action becomes legitimately questionable. In this way, state administration becomes faster and more efficient, and human errors are reduced to a minimum. Does this mean that the use of technological achievements in this segment necessarily leads to reductions in the number of employees? Not necessarily, though the state administration should be small (as far as possible) and efficient. Capable and robust management should provide a good internal organization that includes training and directing officers to areas that are highly risk-averse to enforcing tax and customs duties (and others) in accordance with the law.

Obviously, the availability of various tools and the latest developments, such as the use of Blockchain technology and other technologies, lead to changes in the existing 
NBR

1,1

Page 65

paradigm. Can technology development be stopped? No, the world goes further, as depicted in the history. Should this development be stopped at all? Of course not. The development of new technologies allows and will further enable the achievement of goals that have long been the goals of any state administration whose primary purpose is to serve its citizens in the fulfilment of their obligations and the exercise of their rights.

\section{DIGITALISATION AND ADVANCED ANALYTICS}

The digital economy changes our interactions, shopping and business. Digital companies grow much faster than the economy in general, a trend that will continue. Digital technologies bring numerous benefits to society and, from the point of view of taxation, create opportunities for tax administrations and provide solutions for reducing administrative burdens, facilitating co-operation among tax authorities, as well as combating tax evasion.

In the past, the mutual linkage of legislation, as the rule of law in a particular country, and the development of technology, especially in the field of information technology and artificial intelligence, has often escaped needed attention. New time for ever faster and more continuous technology development requires legislators to focus on this particularly important component. While this applies to legislation in general, it is particularly interesting and important in tax legislation. Focus and attention to the development of technology and recent achievements in this area also affect the creation of executive power policies and tax policies. In adopting and applying fiscal and monetary policy, the state's fundamental strategic goals certainly include growing Gross Domestic Product (GDP), production, investments particularly green investments - and employment, as well as stable and stimulating tax policies, price stability (inflation), economic liquidity, monetary equilibrium, currency and exchange rate stability, low interest rates, rising money supply, loyal market competition.

Tax policy supports not just fiscal components, but also wider goals: fostering equal regional development, allowed state aid especially in the area of education, research and development projects, de minimis support, social aspect (exemption from tax payment / tax relief for a certain category of taxpayers), reduction of administrative burden, administrative costs of entrepreneurs, efficient, optimally organized, educated tax and customs administration etc. Tax legislation should be structured, simple, transparent, understandable, and accessible. Such goals are not always easy to achieve, but without the effort to reach taxpayers (partners and stakeholders) the burden of tax administration will be greater than necessary. That effect will be reflected in their business, liquidity, and capital. This will, in turn, affect all economic policies, and thus, the quality of life of all citizens.

\section{Advanced analytics}

Over the last 10 years $s_{L}$ tremendous progress has been made in gathering, organizing, storing and managing global data. As a result, activities that used to require a lot of time now take just a few minutes. These transformations that are a consequence of administrations to understand, analyse, and act upon information available to them. administrations already use the wealth of information they have in order to better 
NBR

1,1

Page 66

technological advances allow tax Many tax understand their taxpayers and occurrences that appear to improve their efficiency and operational efficiency, provide better services to taxpayers, achieve better results with existing or less resources, direct their attention to the riskiest taxpayers, etc. In this way, not only does the tax administration realize cost savings, but also taxpayers express greater satisfaction with the work of the tax administration as a whole. This is because, in addition to receiving better service or assistance in meeting their tax obligations, compliant taxpayers feel diminished pressure and repression due to frequent oversight. They place greater trust in tax administration because attention is focused on those who really avoid tax payments, thereby allowing healthy competition and achieving fairness in taxation. Additionally, advanced analytics allows tax administrations to quickly and accurately identify taxpayers who use fraud or evasion schemes, which can also deter other taxpayers from using those schemes.

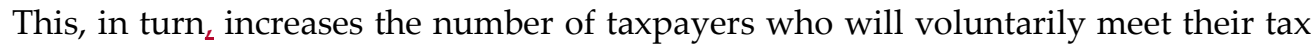
obligations.

The use of advanced analytical technology is detailed in the Organisation for Economic Cooperation and Development $(\mathrm{OECD})^{7}$ report entitled "Advance Analytics for Better Tax Administration: Putting Data to Work" issued in 2016 (summarized below).

In this report, "advanced analytics" is defined as the practice of using statistical techniques for predicting and making conclusions about the causes and consequences of certain behaviour. From its initial use for surveillance purposes, advanced analytics has increasingly been used in other areas, such as optimizing debt management, tax registration and tax payments, improving tax services, and better understanding the impact of tax policy change. Therefore, advanced analytics has increasingly become the cornerstone of operational and strategic decision-making in modern tax administrations.

Projects related to advanced analytics can be divided into 2 categories:

- Predictive analytics - aims to anticipate possible problems, so that tax administrations can take appropriate action; this is usually about recognizing the occurrence, i.e. recognizing the link between the data, but not necessarily the nature of that connection; is based on the principle of trial and error in detecting the occurrence of historical data, and this is then used as the basis for prediction.

- Prescriptive analytics - helps tax administrations to recognize the impact of their activities on the behaviour of taxpayers in order for tax administrations to choose the best activities for a particular group or individual taxpayers; it is actually about recognizing the cause, which aims to determine whether our activities are causal or merely coincidental with the change in the behaviour of taxpayers.

Advanced Analytics is a kind of step forward in the use of analytics in the work of tax administration since it allows for data and content analysis with sophisticated behavioural pattern, detecting externalities, experimenting design, network analysis, it does not try to reveal anything fundamentally new, as it tries to carry out these 
NBR

1,1

Page 67

approaches such as recognizing a particular etc. But tasks with a greater emphasis on the data itself, and less focus on human estimates. For example, Australia, New Zealand, Ireland, the United States, the United Kingdom, and Singapore use advanced analytics in the area of taxpayers' choice for monitoring, tax filing and payment taxation, taxpayer service, debt management, and tax policy setting.

The OECD report shows that 15 of the 16 surveyed countries use advanced tax auditing analytics (for example, VAT refunds by analysing a large set of data, analysing social networks on the Internet, etc., defining mistakes or fraud with income tax on wages, especially in the use of relief, etc.). The purpose of these models is actually to be found on the basis of past data, that is, cases where a fraud or error of a certain common occurrence was discovered and incorporated into a system of risk recognition in future cases, so that a tax administration could anticipate these frauds or errors. However, this type of model will not recognize new or previously unknown types of risk. It is therefore necessary to apply non-standardized models that focus on the data and certain anomalies, rather than learning about the results of specific cases. Such models apply the Australian "nearest neighbours" model, created to find errors or inaccurate data on income tax deductions, or the Irish "income-consumption" model that seeks out unreported income. Both are based on the same principle: comparing the tax returns of similar taxpayers. Both models are very useful, and which model a tax administration chooses will actually depend on the goal to be achieved: if it wants to eliminate interventions that will not result in new obligations, a supervised model will be applied, while if it wants to identify new types of fraud or risk which have not been disclosed so far, it will use a non-standardized model.

\section{BUSINESS ACTIVITIES THROUGH NEW BUSINESS MODELS}

One of the major changes in the economy of digitalisation is the rapid growth of multi-faceted online platforms, which often facilitate transactions between individual sellers of goods and services and peer-to-peer transactions (P2P), which take place outside traditional business structures. In particular, online platforms facilitate growth and development of the "sharing economy" (sometimes referred to as the "collaborative economy" or "gig" economics). Although the terms "sharing economy" and "collaborative economy" are often used interchangeably, when it comes to business models that reflect the existence or absence of taxable receipts, these two concepts may differ as follows:

- "sharing economy" involves common spending, i.e., sharing of costs or the joint use of an individual's property or services, without any additional income or revenue being generated for those who offer it. This is for example the portal "BlaBlaCar" that connects individuals traveling to the same general area and sharing the cost of the route, but the maximum cost that one can offer for transportation with his or her personal car is limited so that no surplus revenue is generated. An example of this kind of collaboration is the portal "homeexchange" that connects individuals to different locations around the world and allows them to exchange vacation homes for free. This kind of economy does not actually create any added value in terms of increasing 
NBR

1,1

Page 68

material benefits for users, and for now, there may be no incentive for tax administrations to introduce taxation;

- "collaborative economy" or co-operation economics involves online business through social online channels, such as privately renting property via platforms such as Airbnb or Booking, online transportation services such as Uber, and professional sales via online platforms such as eBay. In this business model, which merges supply and demand, the users of this portal that provide their services receive a material benefit, thus creating a heightened interest of the tax authorities to tax user receipts.

The "Gig" economy refers to a labour market characterized by the prevalence of short-term and often non-standard contracts or self-employment, unlike permanent jobs and standard labour contracts. This is an environment in which temporary jobs are common, and organizations engage independent and self-employed workers for short-term assignments. Examples include occasional household cleaning services, etc. In this digital age, the workforce is becoming more mobile, and work can be done more and more from anywhere, reducing the connection between the job and location where it is performed. This means freelancers can choose between temporary jobs and projects across the globe, while employers can choose the best individuals for specific projects from a larger "worker pool" than available in just one area.

The economy of cooperation is a relatively new term. While it does not present the same risks associated with cash transactions, some tax administrations have already begun to analyse the risks of tax evasion and tax fraud associated with this type of economy. Pricewaterhousecoopers(PWC) estimated that the divisional economy now generates $\$ 15$ billion of revenue worldwide, and could increase to $\$ 335$ billion by 2025.Some tax administrations have started activities in this area to reduce tax evasion through technological antitrust and regulatory and legislative frameworks. International co-operation may be of help in this area, especially because online platforms are located outside the country where its users live.

\section{CRYPTO CURRENCY: NEW ERA}

We can find a lot of definitions of bitcoin and crypto (or virtual) currency in general on the Internet, but from a legal point of view when we are talking about taxation, this issue is not regulated nor prescribed by law in every country. European Member States must take into account judgment of European Court of Justice (ECJ) C-264/14, on 22 October $_{\llcorner}$2015. Namely, bitcoin was the subject of a dispute between Skatteverket (Swedish tax authority) and Mr. D. Hedqvist in 2015 and the Supreme Administrative Court of Sweden sent a request for a preliminary ruling to the ECJ on whether transactions to exchange a traditional currency for the bitcoin virtual currency or vice versa, which Mr Hedqvist wished to perform through a company, were subject to value added tax (VAT).

In the judgment it positions that, referring to a 2012 report by the European Central Bank on virtual currencies, the requesting court states that the virtual currency can be defined as a type of unregulated digital money issued and verified by its developers, and which is accepted among members of the specific virtual 
NBR

1,1

Page 69

community. The virtual currency, Bitcoin, belongs to the so-called "virtual currency" with a bidirectional flow, which users can purchase and sell on the basis of an exchange rate. When it comes to their use in the real world, such virtual currency is similar to other convertible currencies. They allow both real and virtual goods and services to be purchased.

Virtual currencies differ from electronic money, as defined in Directive 2009/110/EC of the European Parliament and the Council of 16 September ${ }_{L} 2009$ on the taking up, pursuit and prudential supervision of the business of electronic money institutions amending Directives 2005/60/EC and 2006/48/EC and repealing Directive 2000/46/EC (OJ 2009 L 267, p. 7), in so far as, unlike that money, for virtual currencies the funds are not expressed in traditional accounting units, such as in euro, but in virtual accounting units, such as the bitcoin.

Furthermore, in the judgment it is stated that, since the virtual currency bitcoin is a contractual means of payment, on the one hand it cannot be regarded as a current account, a deposit account, a payment, or a transfer. On the other hand, unlike a debt, cheques, and other negotiable instruments referred to in Article 135(1)(d) of the VAT Directive, the bitcoin virtual currency is a direct means of payment between the operators that accept it. The Court therefore concludes that transactions involving non-traditional currencies, that is to say, currencies other than those that are legal tender in one or more countries, in so far as those currencies have been accepted by the parties to a transaction as an alternative to legal tender and have no purpose other than to be a means of payment, are financial transactions. It is also concluded that it is indisputable that the virtual currency bitcoin is neither a security conferring a property right nor a security of a comparable nature.

On those grounds, the Court has ruled that Article 2(1)(c) of Council Directive 2006/112/EC of 28 November 2006 on the common system of value added tax must be interpreted as meaning that transactions such as those at issue in the main proceedings, which consist of the exchange of traditional currency for units of the bitcoin virtual currency and vice versa, in return for payment of a sum equal to the difference between, on the one hand, the price paid by the operator to purchase the currency and, on the other hand, the price at which he sells that currency to his clients, constitute the supply of services for consideration within the meaning of that article, and that Article 135(1)(e) of Directive 2006/112 must be interpreted as meaning that the supply of services such as those at issue in the main proceedings, which consist of the exchange of traditional currencies for units of the bitcoin virtual currency and vice versa, performed in return for payment of a sum equal to the difference between, on the one hand, the price paid by the operator to purchase the currency and, on the other hand, the price at which he sells that currency to his clients, are transactions exempt from VAT, within the meaning of that provision.

The judgment is in reality about transactions performed by an exchange office. Namely, this is one way by which a natural or legal person can become the owner of a crypto currency (by exchanging some of the so-called fiat currencies for bitcoins or other crypto currencies on various web portals offering such a service). 
NBR

1,1

Page 70

In addition, crypto or virtual currency can be purchased or exchanged for one of the fiat currencies at specialized ATMs. Several bitcoin ATMs exist today in Croatia and there are also some domestic entrepreneurs who accept bitcoins as a means of payments for tourist accommodation or other services (hairdressing services, etc.).

In addition to crypto currencies serving as internet payments, they are traded like any other currency and (as well as any currency or commodity on the market) - their value can change significantly. Since the trading of crypto currencies is not monitored nor regulated by any institution, there is a high volatility in price and this provides the opportunity for a large profit, but also for losses for those without experience.

Anonymity is a benefit of crypto currencies that is often mentioned as an advantage. However, trading, including purchasing of crypto currencies is not entirely anonymous. Namely, buying crypto currencies on some of the on-line platforms, such as Coinbase, Litebit, or Cex, where this process is the simplest, requires login identification due to KYC and AML laws (know-your-customer and anti-money laundering). Identification usually consists of sending pictures or copies of personal documents such as passports or ID cards, and photos of the user with it. Some platforms also require a user to be photographed with the bank card the user plans to use for payments. At the moment of sending this data to a selected platform, bitcoin for these users becomes equally anonymous as a bank account. The same can be compared with shares or other securities trading platforms, which also require a similar way of identification. Furthermore, since the entire bitcoin Blockchain is public, it is sufficient for the user of an address to make a mistake just once and publicly announce that the same belongs to him/her (for example if he/she purchases goods with bitcoins on a website that requires a user account, or if he/she views the balance of his/her address on a public computer).

Once a person's identity is associated with an address, the movement of his crypto currencies is easy to follow. Furthermore, crypto currencies transactions can also be monitored via the IP address of the computer from which these transactions are performed and through the so-called transaction graph and other methods. Finally, by exchanging the crypto currencies for national currency and putting the money in the bank account or purchasing of goods of higher value (cars, real estate etc.) this information can be used by the tax administration to investigate the source of funds for which that asset has been acquired or that was put in the bank account.

\section{BLOCKCHAIN AND DISTRIBUTED LEDGER TECHONOLOGIES: POSSIBILITIES FOR TAX ADIMINISTRATIONS}

The World Economic Forum (WEF) has identified Blockchain technology as one of its six mega-trends in a new report broadly aimed at outlining the expected transition to a more digital and connected world. Compiled by the WEF's Global Agenda Council on the Future of Software and Society, the report included the results of a survey of more than 800 information and communications executives and experts. Perhaps most notable among the poll's findings was that those surveyed believe the "tipping point" for government use of the Blockchain will occur by 2023. For purposes of the survey, Blockchain technology was broadly 
NBR

1,1

Page 71

defined as "an emerging technology [that] replaces the need for third-party institutions to provide trust for financial, contract and voting activities".

Blockchain is a ledger that can be added to but not modified, making it very secure. Each entry is secured into blocks of entries, and each new block is linked to the previous one. Blockchain is historically known as a core part of the digital currency bitcoin but can be used for any transaction of value.

Distributed Ledger Technology (DLT) refers to a novel and fast-evolving approach to recording and sharing data across multiple data stores (or ledgers). This technology allows for transactions and data to be recorded, shared, and synchronized across a distributed network of different network participants. When data is stored in proprietary databases, it's difficult to share that data with others without it becoming changed and lost in other databases. DLT creates a single source of truth that all participants can trust. When data is added to a distributed ledger, anyone with an internet connection can access it by connecting to any node in the network.

Tax administrations are part of the influence of new technologies that are developing within The Fourth Industrial Revolution. Their reactions and actions must be timely. The primary purposes of tax administration are to collect tax revenues in accordance with the laws, but also to service taxpayers. Taxpayers must, amongst other things, have a simple, fast, secure ${ }_{\iota}$ and cost-effective way of exchanging information with tax administrations and vice versa, tax administrations with taxpayers. Additionally, in the same efficient way, tax administrations must ensure the exchange of data is in accordance with laws and international agreements, and with other institutions at national and international level, as well as internally. In communications, tax administrations must in particular ensure:

- Quality data warehouse: minimize error data, real-time data and data usage (data should not be for the own purpose only, without using them)

- Security and data protection

- Controlling data, especially their immutability

Exchange quality data in a way:

- Timely and in the shortest possible time (effectiveness in the prevention of tax fraud, but also exchange of data with the taxpayer, which affects the increase compliance)

- Lower cost for both sides.

- Timely detection and prevention of taxpayers' risk behaviour, as well as internal risks

- Predictive analyses for future preventive communication. POSSIBLE SUGGESTIONS

Tax administrations must monitor, analyse, and test new technologies in order to make quality solutions solely for priority. Anonymity of data is not acceptable. The data must be accurate in a visible way so that all relevant information for tax administration can be read from them. However, it is clear that new technologies such as Blockchain and DLT can provide, in certain segments, better communication with tax administrations. Immutability data, use of smart contracts, and real-time 
NBR

1,1

Page 72

data are just some of the benefits.

Considering that tax administrations communicate with a huge amount of data, attention to the selection and implementation of new technologies is of particular importance. In addition, new technologies also contain certain disadvantages, but this should not be a reason for a-priori withdrawal. High quality analyses and studies can provide the best solution for the digital era. Tax administrations should be ready at this time to accept all the challenges posed by digital evolution. Movement is possible only forward.

\section{References}

1. Cipek,K. UljanićŠkreblin, I.: Digitalisation as a way to improve voluntary tax compliance (2018) available on https://www.world.tax/articles/digitalisation-as-away-to-improve-voluntary-tax-compliance.php

2. Cipek, K. UljanićŠkreblin, I.: Tax Treatment of Crypto Currency in Croatia (2018) available on https://www.world.tax/articles/tax-treatment-of-crypto-currency-incroatia.php

3. Cipek,K. Uljanićškreblin, I.: Legislation and Technology:The Paradigm is Changing (2018) available on https://www.world.tax/articles/legislation-and-technology-theparadigm-is-changing.php

4. https://www.weforum.org/focus/fourth-industrial-revolution

5. https://www.coindesk.com/world-economic-forum-governments-blockchain

6. https://cloudblogs.microsoft.com/industry-blog/government/2019/04/16/couldblockchain-become-governments-best-ally-in-driving-tax-compliance/

https://docs.iota.org/docs/getting-started/0.1/introduction/what-is-dlt

7. OECD (2016), Advanced Analytics for Better Tax Administration: Putting Data to Work, OECD Publishing, Paris, https://doi.org/10.1787/9789264256453-en

8. WEF: Deep Shift Technology Tipping Points and Societal Impact Survey Report, September 2015

\section{About Author}

Ksenija Cipek is based in Zagreb, Croatia and she is a lecturer at the local University of Law, a Member of European Law Institute, Contribute Member of the Blockchain Chamber of Commerce (US), Member of the Government Blockchain Association and Board Advisor of EUCED (European Network for Economic Cooperation and Development). Ksenija has over 20 years' experience working at the Ministry of Finance, Tax Administration. She is a highly respected and recognised international tax expert who has heavily involved in law-making and was responsible for many tax reforms. She participates at the Forums and working groups at the Council of the EU, the OECD and IOTA and is speaker at international conferences. As a Project Leader she established Compliance Risk Analysis System and provided idea solution for automatic VAT return based on Risk Analysis System in Croatian Tax Administration. Ksenija is also an author and books writer.

The Corresponding Author KsenijaCipek can be contacted at:ksenija.cipek@gmail.com 